\title{
Streptococcus suis
}

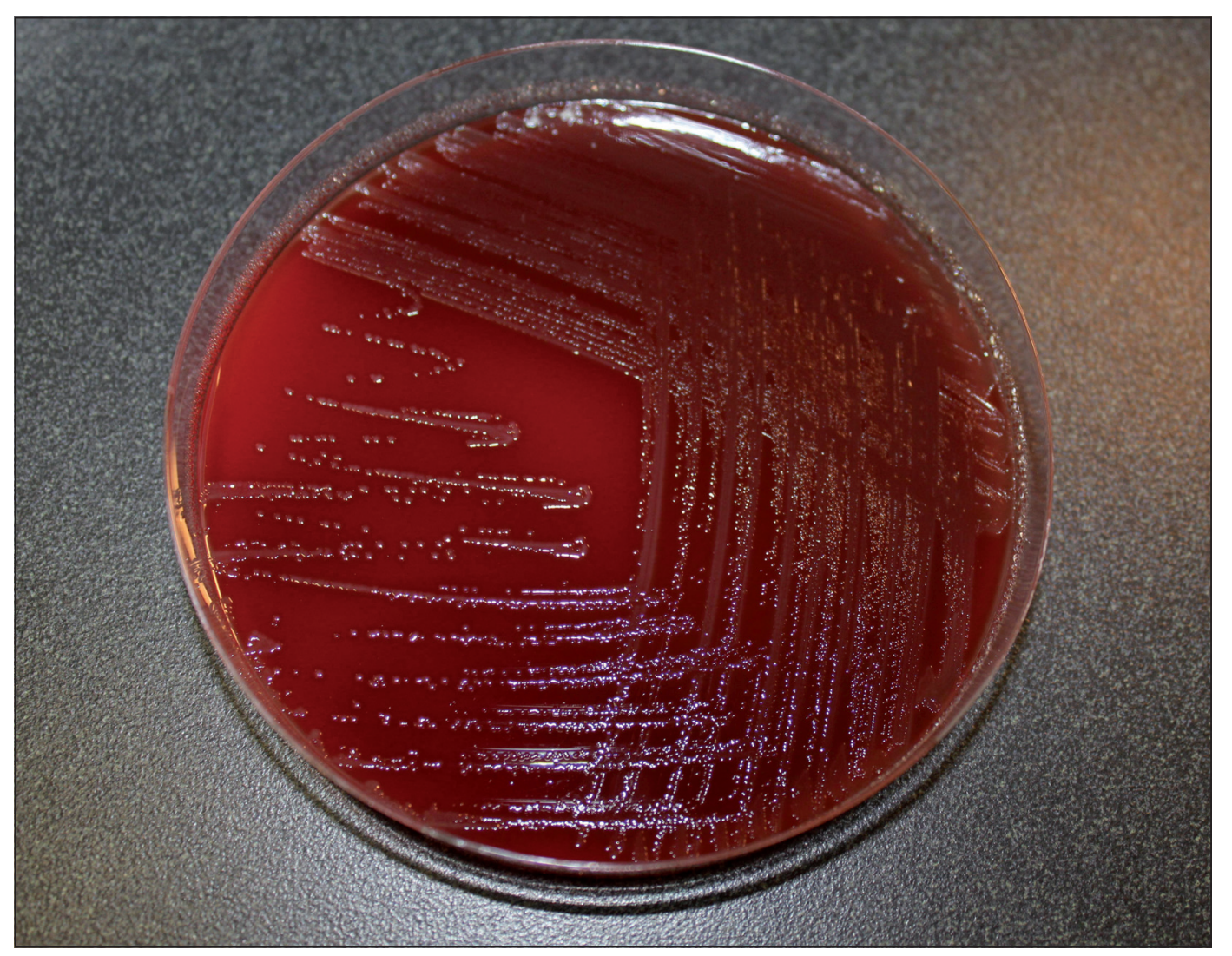

Figura 1. Colonias de Streptococcus suis en agar sangre de cordero. 


\section{Streptococcus suis}

Streptococcus suis es una cocácea grampositiva, perteneciente a la familia Streptococcaceae. Es un importante patógeno de cerdos y ocasionalmente afecta a humanos. El primer caso de infección por $S$. suis en humanos fue reportado en 1968 en Dinamarca. Las infecciones ocurren principalmente en personas que trabajan con cerdos, constituyendo una enfermedad zoonótica. El cuadro clínico en el humano puede manifestarse como una meningitis purulenta, shock séptico, falla multiorgánica, endocarditis, neumonía, artritis o peritonitis. Streptococcus suis se puede aislar en hemocultivos y LCR.

Streptococcus suis posee una cápsula que permite la identificación de 35 serotipos, siendo el serotipo 2 el que se aísla mayormente en cuadros de meningitis, tanto en cerdos como en humanos. Crece en agar sangre de cordero como pequeñas colonias b-hemolíticas con un diámetro de 0,5-1 mm, grisáceas o transparentes y levemente mucoides; en la tinción de Gram se observan cocáceas ovoides; pueden aparecer aisladas, en pares y en cortas cadenas. Es inmóvil, catalasa negativa, presenta metabolismo fermentativo produciendo ácido a partir de algunos azúcares y es anaerobio facultativo. Además es leucino-amino- peptidasa (LAP) positiva y pirrolidonyl-arylamidasa (PYR) negativa. Es resistente a optoquina. Las principales pruebas bioquímicas para su identificación se muestran en la Tabla 1. Corresponde a los grupos R, S, RS y T de Lancefield, aunque algunos pueden reaccionar con el grupo D. Los antimicrobianos de mayor actividad in vitro son los $\mathrm{C-lactámicos,} \mathrm{cotrimoxazol} \mathrm{y} \mathrm{cloranfenicol.}$

\begin{tabular}{|c|c|c|c|}
\hline Prueba Bioquímica & Resultado & Prueba Bioquímica & Resultado \\
\hline $\mathrm{Nacl} 6,5 \%$ & Negativo & Hidrólisis Hipurato & Negativo \\
\hline Bilis esculina & Negativo & Glucosa & Positivo \\
\hline Hidrólisis Arginina & Negativo & Trealosa & Positivo \\
\hline Manitol & Negativo & Maltosa & Positivo \\
\hline Sorbitol & Negativo & Manosa & Positivo \\
\hline Rafinosa & Positivo & Sacarosa & Positivo \\
\hline Lactosa & Positivo & Hidrólisis Almidón & Positivo \\
\hline Hidrólisis Urea & Negativo & Betaglucoronidasa & Positivo \\
\hline Hidrólisis Esculina & Positivo & Test Camp & Negativo \\
\hline Vogues proskauer & Negativo & DNAsa & Negativo \\
\hline
\end{tabular}

\section{Referencias bibliográficas}

1.- Baez M, Espinoza I, Vichi J. Estudio de la sensibilidad in vitro frente a diferentes antimicrobianos en cepas de $S$. suis asociados a neumonía porcina. Rev Salud Anim 2012; 34: 57-62.

Pedro Alarcón Instituto de Salud Pública

Correspondencia a: Pedro Alarcón L. palarcon@ispch.cl 